\title{
Química y Funcionalidad Biológica de Mollinedia racemosa (Monimiaceae)
}

\author{
Elizabeth Murillo, Oscar Lombo y Jonh J. Méndez \\ Universidad del Tolima, Facultad de Ciencias, Departamento de Química, Grupo de Investigación \\ en Productos Naturales. Barrió Santa Elena, Ibagué, Tolima-Colombia. \\ (e-mail: emurillo8@hotmail.com; oslovid@gmail.com; jmendez@ut.edu.co)
}

Recibido May. 04, 2010; Aceptado Jul. 08, 2010; Versión Final recibida Ago. 02, 2010

\section{Resumen}

En este trabajo se caracterizó la especie Mollinedia racemosa, colectada en Yopal-CasanareColombia, desde el punto de vista del perfil fitoquímico, cuantificación de algunos de sus metabolitos secundarios, potencial antioxidante, composición y perfil químico del aceite esencial, de su actividad antimicrobiana y de su toxicidad aguda. Con ello se busca dar soporte científico al conocimiento empírico de comunidades indígenas y campesinas colombianas y para aportar al mejor conocimiento de esta familia vegetal en Colombia. El extracto etanólico de la planta posee un alto contenido de constituyentes fenólicos, en tanto que en los volátiles obtenidos de sus hojas es notable el contenido en sesquiterpenos. La bioactividad revelada por la planta podría estar asociada tanto a los fitofenoles, a sus alcaloides y a los constituyentes de su aceite esencial.

\section{Chemical and Biological Functionality of Mollinedia racemosa (Monimiaceae)}

\begin{abstract}
Mollinedia racemosa, a species collected in Yopal-Casanare-Colombia, has been characterized from the point of view of its phytochemical profile, quantification of some of its secondary metabolites, antioxidant potential, composition and chemical profile of essential oil, antimicrobial activity and acute toxicity. The objective was giving scientific support to the empirical knowledge from Colombian indigenous and peasant communities and to contribute to better understanding of this type of plant in Colombia. The ethanolic extract of the plant has a high content of phenolic constituents, while volatiles compounds obtained from its leaves have high content of sesquiterpenes. The bioactivity revealed by the plant could be associated to phytophenols, alkaloids and essential oil constituents.
\end{abstract}




\section{INTRODUCCION}

La familia Monimiaceae comprende un taxón de plantas Magnoliophytas (Magnoliopsidas), pertenecientes al orden Laurales sensu Dahlgren (Dahlgren, 1980), está constituída por 34 géneros y 440 especies distribuídas en el Viejo y Nuevo Mundo, especialmente en regiones tropicales y subtropicales del continente Americano. La mayoría son árboles o arbustos perennifolios de los estratos inferiores de las selvas, con ramificación poco densa, raramente bejucos (aromáticos, usualmente resinosos). Poseen hojas simples y opuestas, siempre verdes, algunas tienen glándulas oleíferas generadoras de aceite esencial casi siempre con olor a limón, otras por el contrario carecen totalmente de olor.

Las comunidades populares hacen uso de estos vegetales en el tratamiento de desórdenes gastrointestinales, enfermedades de la piel, en la terapia de resfriados, la fiebre, dolor de cabeza y reumatismo y en las mordeduras de serpientes (Lopez et al.,1999). Estas plantas son consideradas como tónicos, estimulantes, digestivos y carminativos.

La alta diversidad de especies presentes en la cuenca del Orinoco colombiano, conformada por los departamentos de Arauca, Casanare, Meta, Guainía y Vichada, ha permitido a los habitantes de este territorio desarrollar formas de manejo diferente de los recursos naturales. Históricamente la región se pobló a partir de un intrincado proceso de mestizaje en el que participaron indígenas, españoles, migrantes colombianos, venezolanos, alemanes e italianos que, una vez llegados al territorio, dieron origen a un nuevo grupo poseedor de formas particulares de pensamiento y de relación con su entorno. En particular los grupos indígenas, quienes poseen desde tiempos ancestrales sistemas propios de administración del medio natural, que a pesar de su incidencia en el medio ambiente han causado impactos menos negativos sobre éste. De esta forma, los campesinos de la cuenca del Orinoco colombiano, conocen y manejan una amplia variedad de plantas que cultivan principalmente en huertos caseros. Entre ellas se encuentran el gualanday (Jacaranda mimosifolia), la verbena (Verbena officinalis), el paico o pasota (Chenopodium ambrosioides L), yerbamora (Solanum nigrum), ortiga (Urtica dioica), llantén (Plantago major L.), flor de amapola (Papaver rhoeas) y romadizo (Mollinedia racemosa).

Romadizo es utilizada y valorada por el sistema etnomédico de los sikuani, kuiba y Sáliva y comunidades campesinas de la región de la Orinoquía colombiana para tratar fiebres, dolores de cabeza y problemas de estómago, especialmente en el tratamiento del resfriado y como analgésico; no obstante es poco conocido por el mundo científico provocando, entre otros, un salto generacional que a su vez conlleva a la pérdida de la transmisión oral de los conocimientos populares.

En la literatura pertinente a la temática de interés de este trabajo se encuentran pocas citas relacionadas con estudios químicos de especies de Mollinedia; para citar unos pocos ejemplos: Leitâo et al. (1999), aislaron algunos metabolitos secundarios (flavonoides y alcaloides) y describieron la composición química y propiedades farmacológicas de la familia Monimiaceae, con especial atención a los géneros Mollinedia y Siparuna. El aspecto biológico de estas especies parece aún más escaso: $M$. costaricensis mostró actividad antiarrítmica en un estudio realizado por Lopez et al., (1999); por su parte, la actividad antibacteriana del aceite esencial de Siparuna conica y Siparuna guianensis fue probada por Pino et al., (2008).

No obstante, la gran mayoría de las investigaciones se ubican en Brasil o bien en Costarrica, creándose un vacío bastante importante sobre los vegetales en cuestión a nivel de Colombia. Este trabajo describe algunas características químicas de la especie Mollinedia racemosa y ciertas propiedades biológicas asociadas a la naturaleza de sus constituyentes químicos, buscando con ello dar soporte científico al conocimiento empírico aun no validado de comunidades indígenas y campesinas colombianas y en el propósito de ahondar en el conocimiento de esta familia vegetal a nivel de Colombia. 


\section{MATERIALES Y METODOS}

\section{Material vegetal}

El material vegetal fue colectado en una "mata de monte" (selva de sabana) cerca de la localidad de Yopal-Casanare (Latitud $05^{\circ} 21^{\prime} \mathrm{N}$, Longitud $72^{\circ} 24^{\prime} \mathrm{O}, 28-30^{\circ} \mathrm{C}, 350$ m.s.n.m., precipitación pluvial $1.500-2.500 \mathrm{~mm}$ ). Se recolectó toda la parte aérea, incluídos frutos y corteza del tallo de varias plantas dentro de un perímetro no mayor a $7500 \mathrm{~m}^{2}$, bajo criterios de calidad en cuanto al estado de desarrollo vegetativo y fitosanitario. Un ejemplar fue enviado al Herbario Nacional de la Universidad Nacional de Colombia para la identificación taxonómica de la planta y depositado allí con el número de colección: 530879 .

\section{Preparación del extracto}

Se preparó un macerado etanólico (relación 1:15, vegetal/solvente), renovando el solvente cada $24 \mathrm{~h}$ hasta agotar la muestra. Este procedimiento se repitió tantas veces como fue necesario hasta obtener un extracto crudo, el cual se filtró y concentró a presión reducida en un rotavapor a $45^{\circ} \mathrm{C}$. El producto así obtenido se mantuvo almacenado $\left(4^{\circ} \mathrm{C}\right)$ hasta su utilización.

\section{Caracterización fitoquímica}

Se evaluó la presencia de carbohidratos, azúcares reductores, compuestos fenólicos, flavonoides, cumarinas, saponinas, quinonas, taninos, grupos alfa-aminos libres, cardiotónicos, terpenos y esteroides, lactonas terpénicas, fenilpropanoides y alcaloides. La detección se realizó básicamente según los ensayos cualitativos individuales para cada grupo químico (Marcano y Hasegawa, 2002) y la metodología clásica de fraccionamiento por polaridad de solvente. En todos los casos se verificaron los ensayos a la gota anteriormente mencionados, con cromatografía de capa delgada. La presencia de alcaloides se verificó aplicando una marcha sistemática para la identificación específica de algunos núcleos alcaloidales.

\section{Cuantificación de algunos metabolitos secundarios}

La cuantificación de fenoles totales (FT) se realizó mediante el método de Folin-Ciocalteu, empleando ácido fosfomolíbdico como complejo desarrollador de color (Huang et al., 2005). La curva de calibrado se preparó con ácido gálico. Para la cuantificación de taninos en el extracto de Romadizo se aplicó un método espectrofotométrico que consta de 2 etapas: la etapa $(A)$ donde se cuantificaron los polifenoles totales en el extracto etanólico, y la etapa (B) donde se cuantificaron los polifenoles residuales después del secuestro de los taninos con gelatina (Lastra et al., 2000). Los taninos que precipitan proteínas (condensados) se determinaron por el ensayo de la albúmina de suero bovino. Para extraer los alcaloides totales se siguió el método clásico, donde la muestra se alcaliniza y las bases alcaloidales correspondientes se solubilizan en un solvente orgánico. La cuantificación del metabolito se realizó espectrofotométricamente, comparando la lectura de absorbancia a $450 \mathrm{~nm}$ en una curva de calibrado preparada con morfina.

\section{Extracción del aceite esencial y análisis por CG-EM}

Las hojas de la planta se sometieron a un proceso de hidrodestilación (HD, 2 h) en un equipo tipo Clevenger $(2 \mathrm{~h})$. Al hidrodestilado se agregó sulfato de sodio anhidro, obteniéndose un aceite esencial $(0.3 \%-0.5 \%)$, al cual se le determinaron las propiedades físicas: olor, color, solubilidad en solventes de diferente polaridad (agua, etanol, metanol, diclorometano y $\mathrm{n}$-hexano), índice de refracción y densidad.

La composición química de la fracción volátil y semivolátil del aceite esencial se determinó por CG-EM. La preparación de la muestra se llevó a cabo por dilución e inyección directa del aceite esencial al equipo cromatográfico. El análisis cromatográfico se realizó en un cromatógrafo de gases Agilent Technologies 6890 Plus acoplado a un detector selectivo de masas (MSD, full scan). La columna empleada en el análisis fue DB-5MS (J \& W Scientific, Folsom, CA, EE.UU) 
[5\%-fenil-poli(dimetilsiloxano), $60 \mathrm{~m} \times 0.25 \mathrm{~mm} \times 0.25 \mu \mathrm{m}$ ]. La inyección se realizó en modo Split (50:1), $V_{\text {iny }}=1 \mu \mathrm{L}$. Los compuestos determinados en el aceite esencial de Romadizo se identificaron utilizando las bases de datos NIST, Wiley y Adams.

\section{Actividad antioxidante}

\section{Método del DPPH (1,1-difenil-2-picrilhidracil)}

La capacidad de los antioxidantes de Romadizo para estabilizar el radical DPPH se evaluó aplicando el método descrito por Brand-Williams et al. (2009), en el que una solución etanólica del radical $(20 \mu \mathrm{g} / \mathrm{ml})$ se mezcló con el extracto vegetal $(1: 3$,

muestra/radical) preparado a diferentes concentraciones (1-100 ppm); la mezcla se incubó a temperatura ambiente $(20 \mathrm{~min})$ y se leyó la absorbancia del radical a $517 \mathrm{~nm}$. El porcentaje de degradación del color violeta de las muestras y patrones de referencia fue determinado mediante la ecuación:

$$
\left[\frac{A b s . \text { DPPH }- \text { Abs. muestra }}{A b s . D P P I I}\right] \times 100
$$

El acido ascórbico y el BHT se utilizaron como controles positivos. El control negativo se preparó con todos los reactivos menos la muestra. El ensayo se corrió por triplicado, los resultados son mostrados como la media de estos valores. El porcentaje de degradación del DPPH de la muestra fue graficado versus la concentración $(r=0.995)$. Una curva de regresión lineal se estableció con el fin de determinar la $\mathrm{Cl}_{50}(\mu \mathrm{g} / \mathrm{ml})$, la cual representa la cantidad de muestra necesaria para disminuir en un $50 \%$ la absorbancia del DPPH.

Método del ABTS (2,2'azinobis (3-etilbenzotiazolin 6-ácido sulfónico)

La metodología desarrollada para medir la actividad antirradical de $M$. racemosa frente al radical $\mathrm{ABTS}^{++}$fue la aplicada por Re et al., (1999) el radical se formó tras la reacción del ABTS (7mM) con persulfato potásico $(2,45 \mathrm{mM}$, concentración final) incubados a temperatura ambiente y en oscuridad (16h). Una vez formado el radical $\mathrm{ABTS}^{++}$se diluyó con etanol hasta obtener un valor de absorbancia de 0,700 $\pm 0,100$ a 754nm (longitud de máxima absorción). A $980 \mu \mathrm{L}$ de la dilución del radical $A B T S^{+}$ya generado se le determinó la $A_{754}\left(27^{\circ} \mathrm{C}\right)$, se añadieron $20 \mu \mathrm{L}$ de la muestra (preparada entre 10 y $100 \mu \mathrm{g} / \mathrm{ml}$ ), y se midió de nuevo la $A_{754}$ pasados 7 minutos. La actividad antirradical se calculó a través de la siguiente fórmula:

$\left[\frac{A b s \cdot A B T S-A b s \cdot m u e s t r a}{A b s \cdot A B T S}\right] \times 100$

\section{Actividad biológica}

\section{Actividad antimicrobiana}

Se probó la actividad antimicrobiana basados en el método de difusión en agar en disco (Cvetnic y Vladimir-Knezevic, 2004). Se trabajó con tres cepas bacterianas: Staphylococcus aureus (Gram +, ATCC6538), Salmonella typhi (Gram -, aislada de alimentos) y una levadura Candida albicans (ATCC18804), tomadas de su respectivo medio de crecimiento selectivo a fin de evitar contaminación. El inóculo de prueba con $10^{4}-10^{5}$ células (porción de $0.5 \mathrm{ml}$ ) se extendió sobre agar Müeller Hinton solidificado, para las bacterias, y sobre agar Sabouraud dextrosa, para el caso de la levadura. Se colocaron sensidiscos $(0.6 \mathrm{~cm} \theta)$ sobre el agar, con $25 \mu \mathrm{L}$ del extracto probado en un amplio rango de diluciones preparadas a partir del extracto crudo. También se aplicó el mismo volumen de etanol al $70 \%$ como control negativo. Las cajas de Petri tamaño estándar se 
incubaron $\left(38^{\circ} \mathrm{C}, 24 \mathrm{~h}\right)$. Finalmente se midió el diámetro de inhibición microbiano alrededor del sensidisco (zona clara). El mismo procedimiento se aplicó para los fármacos utilizados como control positivo: piperacilina PRL $(100 \mu \mathrm{g})$ y penicilina P (10 unidades) frente a las bacterias, y el Ketoconazol (200 mg) como control específico para Candida albicans.

\section{Toxicidad aguda}

El efecto tóxico de Romadizo se determinó frente al modelo biológico de Artemia salina, utilizando como sustrato tres fracciones de diferente polaridad obtenidas a partir del extracto etanólico crudo, de esta manera se comparó el nivel de letalidad del extracto completo, una fracción diclorometánica, una hexánica y el residuo hidroalcahólico en un amplio intervalo de concentraciones (10-10000 ppm). Siguiendo el método descrito por McGawa et al (2007), con algunas modificaciones, los huevos del microcrustáceo, obtenidos en un almacén comercial, fueron puestos a eclosionar en agua de mar artificial (3,8\% de salinidad y luz artificial). 24 horas después de haber obtenido los nauplios de $A$. salina, 10 individuos se colocaron en viales de medida estándar con agua de mar artificial ( $5 \mathrm{ml}, 0.5 \mathrm{ml}$ de muestra y 3 gotas de DMSO), un día después se hicieron las lecturas de mortalidad. Los resultados fueron analizados con el programa EPA PROBIT ANALYSIS PROGRAM. La $\mathrm{DL}_{50}$ se determinó con la fracción hexánica, teniendo en cuenta que resultó ser la de mayor letalidad.

\section{Análisis estadístico}

El análisis estadístico se realizó aplicando el programa StatGraphics Centurion Versión XV. Los resultados son expresados como la media \pm D.E. $(n=3)$. El análisis de regresión lineal se efectuó para calcular la relación dosis-respuesta de las soluciones estándares utilizadas y de las muestras analizadas. El grado de correlación entre las variables se expresó a través del coeficiente de correlación $r^{x y}$.

\section{RESULTADOS Y DISCUSION}

\section{Estudio fitoquímico}

El macerado etanólico de las hojas secas de Romadizo fue principalmente abundante en compuestos fenólicos, específicamente: taninos, flavonoides y fenilpropanoides; adicionalmente se notó que el extracto también contenía terpenos y esteroides. Puesto que gran parte de los metabolitos secundarios se encuentran en forma natural como compuestos glicosilados, no resultó extraño detectar la presencia de carbohidratos (Molisch) y, dentro de ellos, los reductores (Benedict).

Todas las pruebas para reconocer el núcleo alcaloidal resultaron positivas (Dragendorff, Mayer, Reicnekato de $\mathrm{NH}_{4}$, Valser y Bouchardat), lo que se confirmó a través de cromatografía de capa delgada (CCD); todo lo cual permitió aseverar que el extracto de la planta contenía este tipo de núcleo secundario. La marcha sistemática de Bandford (prueba del ácido nítrico y Marquis), dio mayores luces, dejando en claro que Romadizo posee alcaloides de tipo morfeólico, tales como morfina, codeína, papaverina, noscapina, entre otros, y del grupo de las anfetaminas y derivados. Los primeros encuentran aplicación como analgésicos para tratar dolores agudos, los segundos elevan la presión sanguínea, contraen los vasos sanguíneos y dilatan los pequeños sacos bronquiales. Estos usos farmacológicos podrían dar soporte, al menos en parte, a las aplicaciones etnomédicas dadas a Romadizo. Importa mencionar que Monimiaceae es una familia vegetal rica en alcaloides del tipo bencil tetrahidro isoquinoleínas (Leitao et al., 1999). Aunque estos alcaloides presentan actividad dopaminérgica (Arango, 2002), sólo la papaverina, una bencilisoquinoleína, se usa en terapéutica dada su escasa inactividad sobre el sistema nervioso central; esta molécula es un espasmolítico que relaja la musculatura lisa sobre todo a nivel de vasos de la región cerebral, pulmonar y periférica. 


\section{Cuantificación de algunos metabolitos secundarios}

El contenido de algunos de los metabolitos secundarios determinados en el macerado etanólico de $M$. racemosa es visualizado en la Tabla 1. Se observa un valor elevado de fenoles totales, el cual fue previsto a través de la caracterización fitoquímica realizada. El contenido de taninos, que muestra la misma tabla, resulta comparable a los niveles obtenidos en algunas especies maderables (Rosales y González, 2003) pese a que Romadizo es un árbol de mediano porte. Cabe destacar que el $63 \%$ de los taninos detectados son de tipo condensado; recientes investigaciones han demostrado que estos compuestos, denominados también "antialimentarios", poseen actividad anticáncer y antioxidante (Tang et al., 2009).

Tabla 1: Cuantificación de metabolitos secundarios en el extracto de $M$. racemosa

\begin{tabular}{|c|c|c|}
\hline Metabolito & $\begin{array}{c}\text { Contenido } \\
(\mathrm{mg} / \mathrm{g})^{1}\end{array}$ & $D E$ \\
\hline Fenoles totales & $360^{2}$ & \pm 0.02 \\
\hline Polifenoles totales & $41.4^{3}$ & \pm 0.01 \\
\hline Polifenoles no-tanoides & $0.7^{3}$ & \pm 0.01 \\
\hline Taninos totales & $40.3^{3}$ & \pm 0.10 \\
\hline Taninos condensados & $25.1^{3}$ & \pm 0.10 \\
\hline Taninos hidrolizables & $15.2^{3}$ & \pm 0.20 \\
\hline Alcaloides totales & $27.6^{4}$ & \\
\hline $\begin{array}{l}\text { 1. Expresados como materia seca. 2. miligramos equivalentes de ácido gálico por gramo } \\
\text { de vegetal seco. 3. miligramos equivalentes de ácido tánico por gramo de vegetal seco. } 4 . \\
\text { microgramos equivalentes de morfina por gramo de vegetal seco. }\end{array}$ \\
\hline
\end{tabular}

La diversidad de compuestos fenólicos (fenoles simples, ácidos fenólicos, cumarinas, estilbenos, flavonoides hasta ligninas, lignanos y taninos), son un soporte de la función fisiológica y farmacológica, puede ser consecuencia de la capacidad antioxidante y se relaciona con la variabilidad estructural de estos metabolitos (Heim et al., 2002).

Los antecedentes bibliográficos y las pruebas cualitativas realizadas en el estudio fitoquímico fueron la base para proceder a la cuantificación de los alcaloides presentes en el vegetal. Este parece ser uno de los pocos trabajos interesados en la cuantificación de este tipo de metabolito en especies del género Mollinedia.

El conjunto de resultados presentados en la tabla 1, inducen a pensar en Romadizo como una especie vegetal con potencial antioxidante.

\section{Actividad antioxidante}

Una prueba estándar es muy importante puesto que permite comparar los resultados con diferentes laboratorios y validar las conclusiones. Los ensayos de actividad antirradical frente a los radicales estables DPPH y ABTS son ampliamente utilizados para evaluar la actividad antioxidante. Los resultados obtenidos en las pruebas de actividad antioxidante indican que los constituyentes químicos de Romadizo poseen un alto potencial para estabilizar radicales libres en forma dependiente de la concentración. Pese a que la $\mathrm{Cl}_{50}$ obtenida frente al radical DPPH y ABTS, es superior a la de los estándares (BHT y AA), no por ello resulta despreciable (tabla 2). No debe perderse de vista que se están comparando sustancias puras universalmente reconocidas por su capacidad antioxidante, y una mezcla de compuestos de naturaleza química diversa que bien pueden actuar sinérgicamente o antagónicamente.

Para algunos investigadores la cinética entre las concentraciones del DPPH y los antioxidantes no es lineal, por lo que preferiblemente debe expresarse la actividad antioxidante como $\mathrm{Cl}_{50}$ (Huang et al., 2005). El análisis estadístico aplicado hizo evidente la afirmación anterior en el rango de 
concentraciones utilizadas en este trabajo frente al DPPH. En el caso del ABTS, el estudio estadístico mostró una relación directa dosis-respuesta $\left(R^{2}=0.999\right)$.

Tabla 2: Actividad antioxidante del extracto etanólico de Romadizo

\begin{tabular}{|c|c|c|c|c|}
\hline \multirow{3}{*}{$\begin{array}{c}\text { Concentración } \\
(\mu \mathrm{g} / \mathrm{ml})\end{array}$} & \multicolumn{4}{|c|}{ Radical } \\
\hline & \multicolumn{2}{|c|}{$D P P H$} & \multicolumn{2}{|c|}{ ABTS } \\
\hline & $\begin{array}{c}\text { Inhibición } \\
(\%)\end{array}$ & $\mathrm{Cl}_{50}$ & $\begin{array}{c}\text { Inhibición } \\
(\%)\end{array}$ & $\mathrm{Cl}_{50}$ \\
\hline 10 & $44.85 \pm 0.11$ & \multirow{4}{*}{$14.59 \pm 0.011$} & $45.60 \pm 0.12$ & \multirow{4}{*}{$17.32 \pm 0.12$} \\
\hline 25 & $85.75 \pm 0.15$ & & $54.60 \pm 0.17$ & \\
\hline 50 & $92.87 \pm 0.10$ & & $69.48 \pm 0.11$ & \\
\hline 100 & $90.50 \pm 0.10$ & & $99.20 \pm 0.12$ & \\
\hline \multicolumn{2}{|c|}{$\begin{array}{c}\text { BHT } \\
\text { (butil hidroxi tolueno butilado) } \\
(1-25 \mu \mathrm{g} / \mathrm{ml})\end{array}$} & $5.5 \pm 0.140$ & - & $7.80 \pm 0.20$ \\
\hline \multicolumn{2}{|c|}{$\begin{array}{c}\mathrm{AA} \\
\text { (ácido ascórbico) } \\
(1-25 \mu \mathrm{g} / \mathrm{ml})\end{array}$} & $10.24 \pm 0.983$ & - & $10.48 \pm 0.24$ \\
\hline
\end{tabular}

Los autores han asociado el contenido de compuestos fenólicos con la actividad antioxidante, planteamiento que se cumple bastante bien al correlacionar los valores de estos metabolitos (Tabla 1) y la concentración necesaria para inhibir la cantidad inicial del radical libre $\left(\mathrm{Cl}_{50}\right)$, que muestra la Tabla 2. No obstante, la capacidad antioxidante de un producto vegetal puede también derivarse del efecto combinado de diversos factores, como puede ser la presencia de otro tipo de metabolitos antioxidantes (por ejemplo alcaloides o algunos terpenos, ácido caféico y ferúlico, entre otros) o bien, una actividad pro-oxidativa que se contrapone al potencial antioxidante.

La acción antioxidante de los fitofenoles ha sido ampliamente reconocida como derivada de su capacidad para estabilizar especies reactivas del oxígeno, pero si se tiene en cuenta la alta inestabilidad energética y cinética de las especies reactivas del oxígeno, se puede pensar que la capacidad para inhibir radicales libres de los polifenoles es la menos factible, y que más bien pueden actuar bloqueando la formación de aquellas especies por interacción con sus precursores: anión superóxido y el peróxido de hidrógeno, predecesores del radical hidroxilo, considerado como el más potente oxidante entre ellas.

Otra posibilidad es que los compuestos fenólicos actúen como quelantes de metales de transición como el cobre y el hierro, colaboradores en la formación de las especies en cuestión a través de las reacciones de Fenton-Haber.Weiss (Pardo et al., 2005), lo que reduciría la toxicidad de la célula. La acción sinergística de ambos mecanismos podría explicar los valores relativamente bajos de la $\mathrm{Cl}_{50}$ obtenidas frente al DPPH y al ABTS para Romadizo. De esta forma, un estudio completo de la actividad antioxidante de una planta requiere de la medición de diferentes parámetros. Por otra parte, los fitofenoles han sido reportados por tener actividad anticáncer o anticarcinogénica/antimutagénica, antibacterial, antiviral y antiinflamatoria en mayor o menor grado (Cassidy et al., 2000, Tapiero et al., 2002). Bajo esta consideración, el futuro de la especie que nos ocupa resultaría bastante promisorio.

No obstante en un extracto vegetal crudo esta actividad puede también ser consecuencia de la presencia de otros constituyentes químicos, como es el caso de los alcaloides. El contenido del átomo de nitrógeno convierte a la mayoría de los alcaloides en compuestos capaces de donar electrones y, en consecuencia, capturar radicales libres. Si la molécula del alcaloide contiene grupos funcionales adyacentes que cedan electrones, como por ejemplo los grupos alquilo, la disponibilidad de los electrones del átomo de nitrógeno aumenta.

El análisis químico aplicado al extracto de Romadizo dejó ver que posee alcaloides del tipo bencil tetrahidro isoquinoleínas, la mayor parte de estos compuestos químicos se caracterizan por 
poseer grupos hidroxilos sobre el anillo aromático, permitiéndoles entonces estabilizar radicales libres y generar en consecuencia radicales fenoxi termodinámicamente y cinéticamente estables, ya sea porque se incrementa la deslocalización electrónica en el anillo bencénico o bien porque los análogos no-fenólicos pueden provocar deslocalización del par de electrones libres del nitrógeno, lo cual extiende la conjugación y, por consiguiente, estabiliza aun más el radical (Zhao et al., 2006).

Entonces, la acción conjunta de fitofenoles y alcaloides contenidos en $M$. racemosa dan soporte a la actividad antirradical manifestada por el vegetal, con una $\mathrm{Cl}_{50}$ muy cercana a la del ácido ascórbico, un antioxidante de amplio reconocimiento a nivel farmacológico e industrial.

\section{Análisis químico del aceite esencial}

La identificación de los componentes presentes en el aceite esencial, extraído por HD, se llevó a cabo con base en los índices de retención, el análisis de sus espectros de masas y por su comparación con los espectros en las bases de datos.

La cantidad relativa (\%) de los constituyentes mayoritarios presentes en el aceite esencial de $M$. racemosa, obtenido con un rendimiento de $0.5 \%$, v/w (color amarillo suave, olor fuerte a hierba, soluble en etanol), fueron: curzerenona (33.1\%); espatulenol (19\%); 2-undecanona (5.9\%); transcariofileno (4.3\%); óxido de cariofileno (3.2\%); n-nonanol (2.8\%); biciclogermacreno $(2.6 \%) ; \delta$ amorfeno (1.8\%); elemol (1.5\%), $\alpha$-muurorol (1.7) y $\alpha$-copaeno (1.1\%).

De acuerdo a lo descrito en el párrafo anterior $y$, adoptando el criterio de combinar los constituyentes con un contenido cercano al $20 \%$, en lugar de uno solo, para determinar el quimiotipo del aceite esencial, se estableció que los volátiles de Romadizo se tipifican por el quimiotipo "curzerenona-espatulenol". Sobre esta base y, teniendo en cuenta además a los componentes restantes, es posible afirmar que el perfil de composición de este aceite esencial, en cuanto al tipo de compuesto, corresponde a la vía del mevalonato.

La curzerenona $\left(\mathrm{C}_{15} \mathrm{H}_{18} \mathrm{O}_{2}\right.$, peso molecular 230.302) es una sustancia química poco estudiada y podría decirse que es la primera vez que su presencia se menciona en una especie vegetal de la familia Monimiaceae. En otras plantas su concentración generalmente no supera al $20 \%$ (Soares y Alves, 2004), en tanto que en el aceite esencial de nuestro interés alcanzó un valor del 33.1\%. El compuesto es reconocido por su potencial en el tratamiento de inflamaciones, lo que se ajusta al uso etnomedicinal dado a Romadizo en Casanare-Colombia. Lo anterior permite proponer que la planta, además de las potencialidades ya mencionadas, podría también presentar acción antiinflamatoria asociada a la presencia de la curzerenona, a lo que podrían contribuir los restantes constituyentes, tales como el alcohol sesquiterpénico, espatulenol.

No obstante a que el mecanismo de la acción antioxidante de los aceites esenciales no se conoce con toda certeza, algunos investigadores sugieren que ciertos terpenos actúan como antioxidantes dado que los radicales peroxilos (HOO) que pueden formar reaccionan más rápido que los que logran generarse a partir de los ácidos grasos insaturados (Fotti et al., 2003). Otros autores han mostrado que algunos aceites esenciales y sus fitoconstituyentes poseen la capacidad de atrapamiento del catión-radical $\mathrm{ABTS}^{+}$y del radical DPPH igual o superior a la de antioxidantes sintéticos como la vitamina E, el trolox y el ácido ascórbico (Elzaawely et al., 2007; Al-Reza et al., 2010).

\section{Actividad antimicrobiana y toxicidad aguda}

La tabla 3 deja ver los resultados de los halos de inhibición del extracto etanólico de Romadizo y la de los fármacos utilizados como control positivo. La tabla contiene también los valores tomados como referencia para evaluar la actividad antimicrobiana del extracto vegetal y la de los controles positivos frente a cada organismo específico. El control negativo, etanol al $70 \%$, no mostró ninguna zona de inhibición. 
Tabla 3. Inhibición del crecimiento de bacterias y levaduras por el extracto etanólico de Romadizo comparado con los controles

\begin{tabular}{|c|c|c|c|c|c|c|}
\hline \multirow{3}{*}{ Organismo } & \multicolumn{4}{|c|}{$\begin{array}{c}\text { Diámetro de la zona de inhibición } \\
\text { ( } \mathrm{mm})\end{array}$} & \multicolumn{2}{|c|}{$\begin{array}{l}\text { Valores de } \\
\text { sensibilidad }^{*}\end{array}$} \\
\hline & \multirow{2}{*}{$\begin{array}{l}\text { Extracto } \\
\text { vegetal }\end{array}$} & \multicolumn{3}{|c|}{ Controles } & \multirow[b]{2}{*}{$\begin{array}{l}\text { Resistente } \\
\leq\end{array}$} & \multirow[b]{2}{*}{$\begin{array}{l}\text { Sensible } \\
\quad \geq\end{array}$} \\
\hline & & $\begin{array}{l}\text { Pipera } \\
\text { cilina }\end{array}$ & Penicilina & Ketoconazol & & \\
\hline $\begin{array}{l}\text { Staphylococcus } \\
\text { aureus }\end{array}$ & $17-18$ & 29 & 34 & N. A. & 28 & 29 \\
\hline $\begin{array}{l}\text { Salmonella } \\
\text { typhi }\end{array}$ & $19-29$ & 30 & 17 & N.A & 17 & 21 \\
\hline Candida albicans & $18-26$ & N.A. & N.A. & 26 & 11 & 20 \\
\hline
\end{tabular}

Si se compara la zona de inhibición del extracto con la exhibida por los controles positivos, es posible afirmar que los constituyentes bioactivos de Romadizo son ligeramente activos frente a Salmonella typhi y Candida albicans, al mostrar halos de inhibición que indican sensibilidad de las cepas microbianas utilizadas frente al vegetal (tabla 3). Nuestros resultados son superiores a los alcanzados por otros investigadores trabajando con extractos frente a los mismos organismos utilizados en este trabajo (Cvetnik y Vladimir-Knezevic, 2004).

Cabe hacer mención que el método de difusión en discos, ampliamente utilizado por la comunidad científica, presenta una desventaja: poca o casi nula solubilidad de algunos compuestos en agua, entre ellos los de naturaleza terpénica, los cuales no se difunden a través de un medio acuoso. De esta manera, se puede pensar que los aceites esenciales, ricos en estos terpenoides, darian un "falso" resultado en este bioensayo. Es importante tener en cuenta que Romadizo posee una rica mezcla de compuestos sesquiterpenoides, contenidos en su aceite esencial.

Por su parte, el ensayo de toxicidad con Artemia salina mostró que la fracción más activa frente a este organismo fue la menos polar (hexánica), reforzando la idea de que los compuestos apolares presentes en el vegetal serían el principal soporte de su posible efecto tóxico; sin embargo, el valor de la $\mathrm{DL}_{50}$ sugiere una baja toxicidad en este extracto, ya que resultó superior a10000 ppm.

En países en desarrollo el uso de los antibióticos convencionales puede ser limitado debido a los costos o el difícil acceso a los grandes centros urbanos; sin embargo, las comunidades rurales y los grupos étnicos a menudo tienen una rica tradición de uso de hierbas y otros productos vegetales para tratar las infecciones endémicas; el Romadizo es reportado en algunas comunidades campesinas del Casanare en el tratamiento de infecciones.

Parece importante mencionar que la herencia genética es la razón primaria que influye en las diferencias de composición de los aceites esenciales de una especie, la edad de las plantas conjuntamente con los factores ambientales constituyen un factor secundario. En consecuencia, 
se puede afirmar que las condiciones ecológicas tropicales donde se encuentra Romadizo, determinan la composición y cantidad relativa de sus constituyentes químicos (Tabla1), la actividad antioxidante (Tabla 2), la actividad biológica (Tabla 3) y la composición del aceite de sus hojas.

\section{CONCLUSIONES}

Nuestros resultados contribuyen al conocimiento de la especie vegetal Mollinedia racemosa, colectada en Yopal-Casanare-Colombia desde el punto de vista del perfil fitoquímico, la cuantificación de algunos de sus metabolitos secundarios, su potencial antioxidante, la composición y perfil químico de su aceite esencial, de su actividad antimicrobiana y de su toxicidad aguda. El extracto etanólico de Romadizo posee un alto contenido de constituyentes fenólicos, en tanto que los volálitiles provenientes de sus hojas están constituídos mayoritariamente por los sesquiterpenos curzerenona y espatulenol, que diferencian a esta especie de otras de la misma familia. La bioactividad revelada por la planta podría estar asociada no sólo a los compuestos de naturaleza fenólica, sino además al tipo de alcaloides que posee la planta y a los compuestos que constituyen su aceite esencial. Los resultados obtenidos dan soporte científico al uso popular de Romadizo en el tratamiento del resfriado y como analgésico. Se hace necesario realizar bioensayos de mayor nivel ya que el aceite esencial y el extracto se presentan como prometedores medicamentos alternativos.

\section{AGRADECIMIENTOS}

Los autores agradecen al grupo de investigación en productos naturales de la Universidad del Tolima GIPRONUT y al Departamento de Química de la misma universidad por el apoyo económico y logístico otorgado a esta investigación.

\section{REFERENCIAS}

Al-Reza, S.M y otros 3 autores, Essential oil composition and antioxidant activities of Curcuma aromatica Salisb, Food and Chemical Toxicology, 48, 1757-1760 (2010).

Arango, A.G.J., Alcaloides y compuestos nitrogenados. Universidad de Antioquia, 1-88 (2002).

Brand-Williams, W., M.E. Cuvelier y C. Berset, Use of a free radical method to evaluate antioxidant activity, En: Erdemoglu, $\mathrm{N}$ y otros 4 autores, Journal of Ethnopharmacology,Estimation of antiinflammatory, antinociceptive and antioxidant activities on Arctium minus (Hill) Bernh. ssp. Minus, Elsevier, volume 121, 318-323 (2009).

Cassidy, A., B. Hanley y R.M. Lamuela-Raventos, Isoflavones, lignans and stilbeneslorigins, metabolism and potential importance to human health, Journal of the Science of Food and Agriculture, 80 (7), 1044- 1062 (2000).

Cvetnic, Z. y S. Vladimir-Knezevic, Antimicrobial activity of grapefruit seed and pulp ethanolic extract, Acta Pharmacology, 54, 243-250 (2004).

Dahlgren, R.M.T., A revised system of classification of the angiosperm, Botanical Journal of the Linnean Society, 80 (2), 91-124 (1980).

Elzaawely, A. A., T.D. Xuan y S. Tawata, Essential oils, kava pyrones and phenolic compounds from leaves and rhizomes of Alpinia zerumbet (Pers.) B.L. Burtt. \& R.M. Sm. and their antioxidant activity, Food Chemistry, 103, 486-494 (2007).

Fotti, M. y K. U. Ingold, Mechanism of inhibition of lipid peroxidation by $y$-terpinene, an unusual and potentially useful hydrocarbon antioxidant, Journal of Agriculture and Food Chemestry, 51, 27-58 (2003). 
Heim, K.E., A.R. Tagliaferro y D.J. Bobilya, , Flavonoid antioxidants:chemistry, metabolism and structure- activity relationships, Journal of Nutritional Biochemistry 13 (10), 572- 584 ( 2002).

Huang, D., B. Ou, y R. L. Prior, The Chemistry behind Antioxidant Capacity Assays, Journal of Agriculture and Food Chemestry, 53, 1841-1856, (2005).

Lastra, V.H., Rodríguez, L.E., Ponce de León R. H. y González, S.M.L., Método analítico para la cuantificación de taninos en el extracto acuoso de romerillo, Revista Cubana Planta Medica, 5(1), 17-22 (2000).

Leitao, G G.y otros 6 autores, Chemistry and pharmacology of Monimiaceae: a special focus on Siparuna and Mollinedia, Journal of Ethnopharmacology, 65 (2), 87-102 (1999).

Lopez, J.A. y otros 5 autores, Alkaloids of Siparuna griseo-flavescens, En: Leitaro, G.G. y otros 6 autores mas, Chemistry and pharmacology of Monimiaceae: a special focus on Siparuna and Mollinedia, Journal of Ethnopharmacology, Elsevier Science, Ireland, volumen 65, 87-102 (1999).

Marcano, D. y M. Hasegawa, Fitoquímica orgánica, 586-588, Universidad Central de Venezuela, Consejo de Desarrollo Científico y Humanístico, Caracas, Venezuela (2002).

McGawa, L.J., V Steenkamp y J.N. Eloff, Evaluation of Athrixia bush tea for cytotoxicity, antioxidant activity, caffeine content and presence of pyrrolizidine alkaloids, Journal of Ethnopharmacology, 110, 16-22 (2007).

Pardo G. y otros 5 autores, Mangifera indica L. extract (Vimang) inhibits $\mathrm{Fe}^{+2}$-citrate-induced lipoperoxidation in isolated rat liver mitocondria, Pharmacology Research, 51 (5), 427-435 (2005).

Pino, N., L. Martínez y E. Stashenko, Actividad antibacteriana del aceite esencial de S. conica y S. guianensis especies de la Familia Monimiaceae, Salud, Revista de la facultad de Salud, Universidad Industrial de Santander, XL (2), 140-142 (2008).

Re, R. y otros 5 autores, Antioxidant activity applying an improved ABTS radical cation decolorization assay. Free Radical Biology Medicine, 26, 1231-1237 (1999).

Rosales C. M. y L. R.F. González, Comparación del contenido de compuestos fenólicos en la corteza de ocho especies de pino. Madera y Bosques, 9 (002), 41-49 (2003).

Soares, L. y V. Alves, Estudo fitoquimico e farmacologico dos constituintes fixos e voláteis de Hedychium coronarium J. Köeng. (Zingiberacea), Universidade Federal de Rondônia, Departamento de Química; Laboratório de Pesquisa em Química de Produtos Naturais,( en línea) 2004. www.unir.br/...l. Acceso: 25 de Febrero (2010).

Tang, P. M. y otros 4 autores, Pheophorbide a based photodynamic therapy induces apoptosis via mitochondrial-mediated pathway in human uterine carcinosarcoma, Cancer Biology and Therapy, 8, 533-539 (2009).

Tapiero, H. y otros 3 autores, Polyphenols: do they play a role in the prevention of human pathologies?, Biomedicine and Pharmacotherapy, 56 (25), 200- 207 (2002).

Zhao, Q., Y. Zhao y K. Wang, Antinociceptive and free radical scavenging activities of alkaloids isolated from Lindera angustifolia Chen, Journal of Ethnopharmacology, 106, 408-413 (2006). 
